\title{
Typhoid fever vaccines: a meta-analysis of studies on efficacy and toxicity
}

\author{
Eric A Engels, Matthew E Falagas, Joseph Lau, Michael L Bennish
}

Division of Clinical Care Research, Department of Medicine, New England Medical Center, Tufts University School of Medicine, Box 63, 750 Washington Street, Boston, MA 02111, USA Eric A Engels, research fellow Tupper Research Institute, Division of Geographic

Medicine and

Infectious Diseases,

Department of

Medicine, New

England Medical

Center, Tufts

University School of

Medicine

Matthew E Falagas,

research fellow

Michael L Bennish,

associate professor

Division of Clinical

Care Research,

Department of

Medicine, New

England Medical

Center, Tufts

University School of

Medicine

Joseph Lau,

associate professor

Correspondence to:

Dr Engels

eric.engels@es.

nemc.org

BMJ 1998;316:110-6

\begin{abstract}
Objective: To estimate the efficacy and toxicity of typhoid fever vaccines.

Design: Meta-analysis of randomised efficacy trials and both randomised and non-randomised toxicity studies of the parenteral whole cell, oral Ty21a, and parenteral $\mathrm{Vi}$ vaccines.
\end{abstract}

Subjects: 1866951 subjects in 17 efficacy trials; 11204 subjects in 20 toxicity studies.

Main outcome measures: Pooled estimates of three year cumulative efficacy, year specific efficacy, and incidence of adverse events.

Results: Three year cumulative efficacy was 73\% (95\% confidence interval $65 \%$ to $80 \%$ ) for two doses of whole cell vaccines (based on seven trials); $51 \%$ (35\% to $63 \%$ ) for three doses of Ty21a vaccine (four trials); and $55 \%$ (30\% to $71 \%$ ) for one dose of $\mathrm{Vi}$ vaccine (one trial). For whole cell and Ty21a vaccines, regimens of fewer doses were less effective. Efficacy was shown to be significant for five years for whole cell vaccines, four years for Ty21a vaccine, and two years for $\mathrm{Vi}$ vaccine. Neither the age of vaccine recipient nor the incidence of typhoid fever in the control group (varying from 6 to 810 cases per 100000 person years) affected the efficacy of the whole cell or Ty21a vaccines. After vaccination, fever occurred in $15.7 \%$ (11.5\% to $21.2 \%)$ of whole cell vaccine recipients, $2.0 \%(0.7 \%$ to $5.3 \%)$ of Ty21a vaccine recipients, and $1.1 \%(0.1 \%$ to $12.3 \%)$ of $\mathrm{Vi}$ vaccine recipients.

Conclusions: Whole cell vaccines are more effective than the Ty2la and Vi vaccines but are more frequently associated with adverse events. Whether the added efficacy of the whole cell vaccines outweighs their toxicity will depend on the setting in which vaccination is used.

\section{Introduction}

Typhoid fever remains a substantial public health problem in developing countries. Each year 33 million people become ill and over 500000 people die of this infection. ${ }^{1}$ Typhoid is rare in industrialised nations, though travellers to endemic countries may occasionally acquire the disease. ${ }^{2}$

The interest in vaccines to prevent this disease is long standing. In 1904 the statistician Karl Pearson (in what may have been the first published meta-analysis on any topic ${ }^{3}$ ) reviewed seven studies of a heat inactivated typhoid vaccine conducted in British army units. ${ }^{4} \mathrm{He}$ concluded that these vaccine studies were flawed and that taken together they failed to show the efficacy of the vaccine. Despite Pearson's assessment and concerns about toxicity, this vaccine was later routinely used in the British army.

Since the first report, in 1962, of a randomised controlled trial of a typhoid vaccine, ${ }^{5}$ the results of at least 29 other trials have been published. Whole cell vaccines, consisting of relatively crude preparations of Salmonella typhi administered parenterally, were found to be effective but to have a high incidence of side effects. ${ }^{6}$ Two vaccines developed more recently, Ty21a (an attenuated strain of $S$ typhi administered orally) and Vi (the purified bacterial capsule, given parenterally), have seemed less toxic than the older whole cell vaccines and are thought to be equally effective. ${ }^{2} 8$

Whether any of the available vaccines would be useful in typhoid prevention in the developing world remains uncertain. ${ }^{9}$ None of the efficacy trials directly compared the newer vaccines with each other or with the whole cell vaccines. Furthermore, studies have provided widely varying estimates of efficacy and toxicity, leaving the true benefits of vaccination uncertain. Important factors that might influence the efficacy of the vaccines, such as the age of those vaccinated and their risk of acquiring typhoid fever, have not been systematically assessed.

In industrialised countries doctors may have to advise travellers on their risk of acquiring typhoid and ways to reduce that risk. Indeed, though typhoid vaccines were initially evaluated in populations living in endemic regions, today the vaccines are used mainly for travellers. One third of travellers presenting to doctors for advice are vaccinated. ${ }^{10}$ Most are unlikely to develop typhoid; those at highest risk include travellers making prolonged visits to remote areas of endemic nations. ${ }^{2}$

A clearer understanding of the efficacy and toxicity of typhoid vaccine would be useful for doctors in both developing and developed nations. We therefore conducted a meta-analysis-the first since Pearson's review in 1904 and the first to include randomised controlled trials - to evaluate published data on these vaccines.

\section{Methods}

\section{Literature search and inclusion and exclusion criteria}

To identify published efficacy trials of typhoid vaccines we conducted a literature search of the Medline database from 1966 to 1996. In the search we used the textwords "Salmonella," "salmonellosis," "typhoid," and "vaccine." We also conducted searches of Index Medicus (1955-66), Embase, and The Cochrane Library database. ${ }^{11}$ We obtained additional studies from reference lists of retrieved articles and included studies in any language.

We included only field trials that reported the number of cases of typhoid fever in each arm of the trial. Included trials had control arms in which subjects received either placebo or a vaccine against a disease other than typhoid fever. We grouped vaccines included in this analysis into three classes: the Ty21a vaccine; the $\mathrm{Vi}$ vaccine; and the whole cell vaccines, inactivated with alcohol, formol, acetone, or heat (the 
heat inactivated vaccine is the only vaccine in this class currently widely available).

\section{Data extraction}

From each trial report we extracted the vaccine formulation and the number of doses, age of subjects, duration of follow up, number of subjects, and number of cases of typhoid fever. In all trials the primary means of diagnosing cases of typhoid was isolation of $S$ typhi from cultured blood, but five trials also included cases documented by stool, urine, or duodenal fluid cultures. ${ }^{12-16}$ We noted whether randomisation was adequately described (description of unit of randomisation and method of generating random assignment); whether trial assignment was concealed from investigators; whether diagnosis of typhoid fever occurred blinded to assignment; whether surveillance for cases was active (staff going into the field to identify cases), intermediate (relying on pre-existing clinics, encouraged to evaluate patients for typhoid), or passive (relying on reporting of cases by others, without efforts to increase surveillance); and whether efficacy could be calculated on an "any-dose" basis (data available for subjects getting at least one vaccine dose) or an "all-dose" basis (data available only for subjects getting all assigned vaccine doses). Two of the authors independently extracted these data; discrepancies were resolved through consensus discussions.

\section{Analysis of vaccine efficacy}

Published trials provided efficacy data for regimens with different numbers of doses and after various durations of follow up. For the primary analysis we examined the cumulative efficacy for 2.5-3 years of follow up for regimens with three doses of Ty21a, one dose of $\mathrm{Vi}$, or two doses of whole cell vaccines. We chose these dose regimens because they were $(a)$ the highest dose regimens for which trials presented data on these vaccines and $(b)$ the regimens commonly used in practice. We chose 2.5-3 years of follow up because this was the longest time for which most studies provided data. For each intervention arm of the trials we calculated the incidence of typhoid fever per person year and an incidence ratio (incidence in the intervention arm divided by incidence in the control arm). We calculated these incidences based on any-dose data, but if these were unavailable we used all-dose data. For trials that compared several intervention arms with a single control arm we divided the control arm into equal portions so that we could pool the incidence ratios without counting control subjects more than once. We also separately examined efficacy for different formulations of the Ty21a and whole cell vaccines.

We combined the incidence ratios from each trial using a random effects model, an application ${ }^{17}$ of the DerSimmonian-Laird method. ${ }^{18}$ We report efficacy estimates and 95\% confidence intervals as relative risk reductions (1 minus the pooled incidence ratio, expressed as a percentage). Efficacy was considered significant if the confidence interval did not contain zero.

\section{Analysis of variables influencing efficacy}

For each vaccine class, we separately pooled trial data for each year of follow up and for regimens with different numbers of doses. This allowed us to determine the duration of efficacy and the impact of number of doses on efficacy. For trials reporting data for only part of a year, we rounded duration of follow up to the closest year when deciding for which year of follow up the data would be used.

Some trials of Ty21a and whole cell vaccines also provided age specific data. To examine vaccine efficacy for subjects of different ages, we chose age cut offs that maximised the number of trials providing data for the resulting age subgroups. We then pooled the individual trials' efficacy estimates separately for these age subgroups.

Because the efficacy of an intervention may depend on a population's disease risk, and because the incidence of disease in the control group (the control incidence) is a measure of the trial population's risk of disease, ${ }^{19}$ we examined the relation between trial control incidence and vaccine efficacy. For Ty21a and the whole cell vaccines we performed a weighted least squares linear regression of incidence ratio (log transformed) as a function of the trial's control incidence; we could not do this with the Vi vaccine because only one trial provided data at three years of follow up. For weights in the regression we used: 1/variance estimate for the natural logarithm of the incidence ratio. ${ }^{20}$ Results are reported as confidence intervals for the regression line slope.

\section{Analysis of vaccine toxicity}

Many trials identified for our efficacy analysis did not provide information on adverse events that were associated with the vaccine; we therefore included non-randomised trials and cohort studies in our analysis of vaccine toxicity. We included only studies that used active surveillance for adverse events, and for the whole cell vaccines we restricted our analysis to the currently available heat inactivated vaccine. Because toxicity studies published in languages other than English tended to be small and difficult to obtain, we included only studies in English.

For each study we noted whether it was clinic based or field based, and we recorded the incidence after vaccination of fever, missed work, swelling at the injection site (Vi or whole cell vaccine), and vomiting and diarrhoea (Ty21a vaccine). We used a random effects model to pool logit-transformed estimates of the incidence of these outcomes among vaccine recipients. ${ }^{18}$ For studies that reported toxicity on a "per dose" basis for multidose regimens (instead of "per subject") we counted each dose as a separate subject for pooled estimates. ${ }^{61-26}$

\section{Results}

\section{Trials of vaccine efficacy}

The 17 trials in this meta-analysis included 1866951 subjects (table 1). There were 5 trials of Ty21a (326 689 subjects; 11 vaccine arms), ${ }^{13}{ }^{14}$ 27-29 2 trials of Vi (17 822; $2),{ }^{30}{ }^{31}$ and 10 trials of whole cell vaccines (1 522440 ; 21)..$^{5712151632-35}$ The trials of Ty2la and Vi vaccines used either active or intermediate surveillance; the trials of the whole cell vaccines used passive surveillance (3 trials) or did not describe the surveillance (7). All the trials used some method of concealing the assignment status of subjects, but only 8 trial reports described both randomisation and blinding. Only 3 of 13 trials 
Table 1 Efficacy trials of typhoid vaccines

\begin{tabular}{|c|c|c|c|c|c|c|c|c|c|c|c|c|}
\hline \multirow[b]{2}{*}{ Study } & \multirow{2}{*}{$\begin{array}{c}\text { Country, } \\
\text { year }\end{array}$} & \multicolumn{4}{|c|}{ Study design and reporting* } & \multirow{2}{*}{$\begin{array}{l}\text { Age range } \\
\text { (years) }\end{array}$} & \multirow{2}{*}{$\begin{array}{l}\text { Follow } \\
\text { up } \\
\text { (years) }\end{array}$} & \multirow{2}{*}{$\begin{array}{c}\text { Control } \\
\text { incidencet }\end{array}$} & \multirow{2}{*}{$\begin{array}{l}\text { Arm and vaccine } \\
\text { formulation/dose } \\
\text { interval (days) }\end{array}$} & \multirow{2}{*}{$\begin{array}{l}\text { No of } \\
\text { doses }\end{array}$} & \multirow{2}{*}{$\begin{array}{c}\text { No of } \\
\text { subjects }\end{array}$} & \multirow{2}{*}{$\begin{array}{c}\text { Efficacy } \\
(95 \% \text { CI) }\end{array}$} \\
\hline & & Dose & Surveillance & Randomisation & Blinding & & & & & & & \\
\hline \multicolumn{13}{|l|}{ Ty21a vaccine: } \\
\hline Wahdan et a $\left.\right|^{28}$ & Egypt, 1982 & Any & Intermediate & Yes & Yes & 6 to 7 & 3.0 & 46 & Liquid/2 & 3 & 16486 & 96 (67 to 99$)$ \\
\hline \multirow[t]{4}{*}{ Levine et $\mathrm{al}^{13}$} & Chile, 1987 & All & Intermediate & Noł & Yes & 6 to 21 & 3.0 & 104 & A: enteric capsule/21 & 3 & 21598 & 49 (23 to 66$)$ \\
\hline & & & & & & & & & B: enteric capsule/2 & 3 & 22170 & 67 (46 to 79 ) \\
\hline & & & & & & & & & C: gel capsule/21 & 3 & 21541 & 31 (0 to 53$)$ \\
\hline & & & & & & & & & D: gel capsule/2 & 3 & 22379 & $19(-15$ to 43$)$ \\
\hline \multirow[t]{2}{*}{ 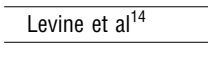 } & Chile, 1990 & All & Intermediate & Noł & Yes & 5 to 19 & 3.0 & 91 & A: liquid/2 & 3 & 36623 & 77 (60 to 87$)$ \\
\hline & & & & & & & & & B: enteric capsule/2 & 3 & 34696 & $33(-4$ to 57$)$ \\
\hline \multirow[t]{2}{*}{ Black et $\mathrm{al}^{29}$} & Chile, 1990 & All & Intermediate & Noł & Yes & 5 to 22 & 5.0 & 120 & A: enteric capsule/7 & 2 & 27620 & 43 (26 to 56$)$ \\
\hline & & & & & & & & & B: enteric capsule & 1 & 27618 & 16 (-6 to 33$)$ \\
\hline \multirow[t]{2}{*}{ Simanjuntak et $\mathrm{al}^{27}$} & $\begin{array}{c}\text { Indonesia, } \\
1991\end{array}$ & All & Intermediate & No & No & 3 to 44 & 2.5 & 810 & A: liquid/7 & 3 & 5066 & 53 (36 to 66$)$ \\
\hline & & & & & & & & & B: enteric capsule/7 & 3 & 5209 & 42 (23 to 57 ) \\
\hline \multicolumn{13}{|l|}{ Vi vaccine: } \\
\hline Klugman et a $^{31}$ & $\begin{array}{l}\text { South Africa, } \\
1996\end{array}$ & Any & Active & Yes & Yes & 5 to 16 & 3.0 & 387 & Not applicable & 1 & 5692 & 55 (30 to 71$)$ \\
\hline \multicolumn{13}{|l|}{ Whole cell vaccines: } \\
\hline \multirow[t]{2}{*}{$\mathrm{YTC}^{5}$} & $\begin{array}{l}\text { Yugoslavia, } \\
1962\end{array}$ & All & Passive & Yes & No & 5 to 50 & 6.0 & 77 & A: heat/21 & $2 \S$ & 11503 & 72 (50 to 84$)$ \\
\hline & & & & & & & & & B: alcohol/21 & $2 \S$ & 12017 & 42 (10 to 62 ) \\
\hline \multirow[t]{2}{*}{$\mathrm{YTC}^{7}$} & $\begin{array}{c}\text { Yugoslavia, } \\
1964\end{array}$ & All & Passive & Yes & No & 2 to 60 & 2.5 & 595 & A: heat/28 & 2 & 5068 & 51 (27 to 67$)$ \\
\hline & & & & & & & & & B: acetone/28 & 2 & 5028 & 79 (63 to 88$)$ \\
\hline Hejfec $^{32}$ & USSR, 1965 & All & ND & Yes & Yes & 7 to ? & 0.7 & 256 & Alcohol/20-30 & 2 & 22269 & 37 (-5 to 62$)$ \\
\hline \multirow[t]{2}{*}{$\begin{array}{l}\text { Hejfec et al }{ }^{33} \\
\text { (USSR 4) }\end{array}$} & USSR, 1966 & All & ND & Yes & Yes & 7 to 18 & 2.5 & 77 & A: heat/20-30 & 2 & 45187 & 82 (69 to 89 ) \\
\hline & & & & & & & & & B: alcohol/20-30 & 2 & 45594 & 54 (34 to 69$)$ \\
\hline \multirow[t]{2}{*}{$\begin{array}{l}\text { Hejfec et al }{ }^{33} \\
\text { (USSR 5) }^{\text {US }}\end{array}$} & USSR, 1966 & All & ND & Yes & Yes & 7 to ? & 2.5 & 62 & A: heat/20-30†† & 2 & 45213 & 86 (72 to 93$)$ \\
\hline & & & & & & & & & B: heat/20-30†† & 2 & 36112 & 66 (43 to 79 ) \\
\hline \multirow{2}{*}{ PTC $^{15}$} & & & & & & & & 69 & B: acetone/28†† & 2 & 116858 & 71 (28 to 88 ) \\
\hline & & & & & & & & 101 & C: formol/28 & 2 & 94290 & 77 (60 to 87 ) \\
\hline \multirow[t]{2}{*}{ Ashcroft et al ${ }^{12}$} & Guyana, 1967 & Any & Passive & Yes & Yes & 5 to 15 & 7.0 & 70 & A: heat $/ 35$ & 2 & 26802 & 67 (54 to 77) \\
\hline & & & & & & & & & B: acetone/35 & 2 & 27365 & 89 (81 to 93 ) \\
\hline Hejfec et a $\left.\right|^{34}$ & USSR, 1968 & Any & ND & Yes & Yes & 7 to 16 & 2.5 & 561 & A: heat†† & 1 & 20832 & 73 (40 to 88 ) \\
\hline & & & & & & & & 339 & B: heat†† & 1 & 68214 & 49 (20 to 67$)$ \\
\hline Hejfec et a ${ }^{35}$ & USSR, 1969 & Any & ND & Yes & No & 7 to 20 & 1.8 & 48 & A: acetone & 1 & 52347 & 51 (8 to 74) \\
\hline & & & & & & & & & B: heat & 1 & 52698 & 59 (19 to 79$)$ \\
\hline Tapa et al ${ }^{16}$ & Tonga, 1975 & All & ND & No & Yes & 2 to 60 & 7.5 & 64 & A: acetone/28 & 2 & 11128 & 40 (6 to 61) \\
\hline & & & & & & & & & B: acetone/28 & 1 & 11391 & $-5(-53$ to 28$)$ \\
\hline
\end{tabular}

YTC=Yugoslav Typhoid Commission. PTC=Polish Typhoid Committee. ND=not described in study.

*Dose: any=data based on subjects getting at least one dose, all=data based only on subjects getting all doses; randomisation and blinding: yes=described, no=not described.

†Cases of typhoid per 100000 person years in the control group.

$\ddagger$ Subjects were randomised by classroom; the method of generating random assignment was not described.

§About $75 \%$ of subjects in each arm received a third dose as a booster after one year of follow up.

१Compared each intervention arm with a separate control arm.

t†Compared different formulations of heat inactivated or acetone inactivated vaccines.

examining multidose regimens reported data on an any-dose basis.

\section{Estimates of vaccine efficacy}

The cumulative three year efficacy of two doses of the whole cell vaccines was $73 \%$, of three doses of Ty21a was $51 \%$, and of Vi vaccine $55 \%$ was effective (only one trial provided cumulative data for up to 3 years) (figure).

For Ty21a vaccine the efficacy of the liquid formulation was $74 \%$ ( $41 \%$ to $89 \%$; 3 trials), of the enteric capsules was $47 \%$ (32\% to $59 \%$; 3 ), and of the gelatin capsules was $25 \%$ ( $-2 \%$ to $45 \%$; 1 ). For the whole cell vaccines, the efficacy of acetone inactivated vaccine was $80 \%$ (61\% to $90 \%$; 4 ), of formol inactivated vaccine was $77 \%(60 \%$ to $87 \%$; $)$, of heat inactivated vaccine was
$73 \%(61 \%$ to $82 \% ; 5)$, and of alcohol inactivated vaccine was $58 \%(34 \%$ to $73 \%$; 3$)$.

\section{Number of doses and duration of follow up}

Table 2 shows the efficacy estimates for specific years of follow up and for varying numbers of doses. Some estimates for Ty2la and Vi vaccine regimens were based on few study arms or subjects.

For the whole cell vaccines, one dose regimens provided significant protection in each of the first two years, and two dose regimens provided significant protection in each of the first five years. Protection provided by two dose regimens was not significant in the sixth and seventh years. ${ }^{5} 1216$

For the Ty2la vaccine, both two and three dose regimens provided significant protection in each of the 


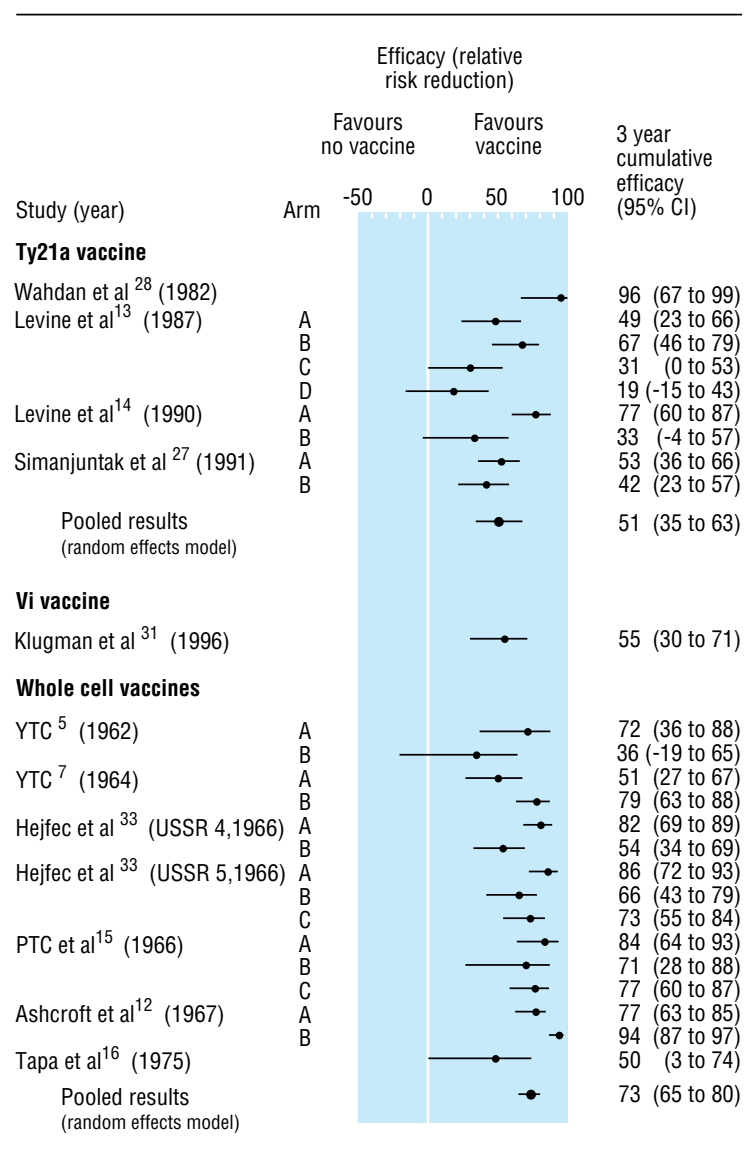

Estimates of three year cumulative efficacy from individual trials (see table 1) and pooled estimates, presented as relative risk reductions (percentages). Individual trial estimates are from arms that provided cumulative data for 2.5-3 years of follow up, for regimens with the following numbers of doses: three doses for Ty21a vaccine, one dose for Vi vaccine, and two doses for whole cell vaccines.

YTC=Yugoslav Typhoid Commission; PTC=Polish Typhoid Committee first two years. The three dose regimen provided significant protection in the third and fourth years but not in the fifth year. Data for efficacy of three doses of the Ty21a vaccine in the fourth and fifth years were from two reports ${ }^{36}{ }^{37}$ that presented extended follow up data for a single arm of a four arm trial ${ }^{13}$; this arm had shown the greatest efficacy at the end of the first three years, but no follow up data were presented for the three less effective arms.

The $\mathrm{Vi}$ vaccine provided significant protection in each of the first two years after vaccination. The protection in the third year was similar to that in the second year but was not significant. No efficacy data were published beyond three years' follow up.

\section{Effect of age and control incidence on efficacy of} vaccines

Efficacy was $80 \%(69 \%$ to $87 \%)$ for ages 2 - 18 years and $62 \%(30 \%$ to $79 \%)$ for ages $15-60$ for the whole cell vaccines $^{72} 1253$ and $71 \%$ (27\% to 89\%) for ages 5-9 and $63 \%(46 \%$ to $75 \%)$ for ages $10-44$ years for the Ty21a vaccine. $^{13} 142728$ The estimates for the Ty21a vaccine are higher than the overall efficacy estimate (51\%) because one study presented no age specific data for the three trial arms with lowest efficacy. ${ }^{13}$

Wide confidence intervals for the linear regression slopes preclude any statement about the relation between efficacy and control incidence. The regression slope was 6.3 ( -40 to 53) for the Ty21a vaccine and 51 ( -24 to 126$)$ for the whole cell vaccines.

\section{Vaccine toxicity}

We identified 20 studies providing toxicity data for 11204 subjects (table 3). Fever occurred after vaccine administration more often with whole cell vaccine than with Ty2 la or Vi vaccines. Swelling at the injection site also occurred more often with the whole cell than the $\mathrm{Vi}$ vaccine. Ty21a vaccine was associated with a $2.1 \%$ incidence of vomiting and a $5.1 \%$ incidence of

Table 2 Percentage (95\% confidence interval) efficacy of typhoid vaccines by number of doses and year of follow up

\begin{tabular}{|c|c|c|c|c|c|}
\hline Vaccine & Year 1 & Year 2 & Year 3 & Year 4 & Year 5 \\
\hline \multicolumn{6}{|l|}{ Ty21a } \\
\hline \multicolumn{6}{|l|}{ One dose: } \\
\hline Efficacy & $25(-9$ to 49$)$ & $35(-8$ to 61$)$ & $1(-87$ to 48$)$ & $-6(-77$ to 37$)$ & $-10(-113$ to 43$)$ \\
\hline \multicolumn{6}{|l|}{ Two doses: } \\
\hline Efficacy & 52 (24 to 69) & 71 (44 to 85$)$ & 22 (-54 to 60$)$ & $19(-41$ to 53$)$ & 7 (-84 to 53$)$ \\
\hline Efficacy & 50 (18 to 69$)$ & 60 (44 to 71$)$ & 60 (35 to 76$)$ & 78 (35 to 93) & $47(-24$ to 78$)$ \\
\hline Patients (No of arms) & $48931(4)$ & $48931(4)$ & 48931 (4) & $22170(1)^{*}$ & $22170(1)^{*}$ \\
\hline \multicolumn{6}{|l|}{$\overline{\mathrm{Vi}}$} \\
\hline \multicolumn{6}{|l|}{ One dose: } \\
\hline Efficacy & $67(44$ to 81$)$ & 52 (4 to 76 ) & $50(-11$ to 78$)$ & No data & No data \\
\hline Efficacy & 65 (49 to 76$)$ & 51 (6 to 74$)$ & 71 (-5 to 92$)$ & $37(-98$ to 80$)$ & 79 (44 to 92) \\
\hline Patients (No of arms) & $290780(11)$ & $132692(9)$ & $96689(7)$ & $18081(3)$ & $18081(3)$ \\
\hline \multicolumn{6}{|l|}{ Two doses: } \\
\hline Efficacy & 74 (62 to 82$)$ & 72 (56 to 82 ) & 74 (50 to 87$)$ & 73 (42 to 87 ) & 67 (43 to 80$)$ \\
\hline Patients (No of arms) & $663491(15)$ & $406310(9)$ & $406310(9)$ & $64617(5)$ & $64617(5)$ \\
\hline
\end{tabular}

The number of patients represents the total number of patients in trial intervention arms providing year specific and dose specific data; the number of arms represents the number of trial intervention arms providing data.

*Data are from Levine et al. ${ }^{36} 37$

†Some data come from studies reporting cases of typhoid in subjects who were randomised to, but failed to complete, two dose regimens. 
Table 3 Toxicity studies of typhoid vaccines

\begin{tabular}{|c|c|c|c|c|c|c|c|c|}
\hline Study & $\begin{array}{l}\text { Age range } \\
\text { (years) }\end{array}$ & $\begin{array}{l}\text { Type of } \\
\text { study }\end{array}$ & $\begin{array}{c}\text { No of } \\
\text { subjects } \\
\text { vaccinated }\end{array}$ & Fever $(\%)$ & Swelling (\%) & Vomiting (\%) & Diarrhoea (\%) & $\begin{array}{l}\text { Missed school } \\
\text { or work (\%) }\end{array}$ \\
\hline \multicolumn{9}{|l|}{ Ty21a vaccine: } \\
\hline Gilman et $\mathrm{al}^{38}$ & Adults & Clinic & 155 & 1 & NA & 3 & 10 & ND \\
\hline Murphy et al ${ }^{39}$ & $0.5-2$ & Clinic & 18 & 11 & NA & 17 & 11 & ND \\
\hline Rahman et al ${ }^{40}$ & $3-78$ & Clinic & 157 & 2 & NA & 0 & 1 & ND \\
\hline Cryz et al ${ }^{41}$ & $2-6$ & Clinic & 317 & $<1$ & NA & 1 & $<1$ & ND \\
\hline Cryz et al ${ }^{21}$ & $16-56$ & Clinic & 30 & 2 & NA & 0 & 20 & ND \\
\hline $\begin{array}{l}\text { Pooled estimate } \\
(95 \% \mathrm{Cl})\end{array}$ & & & & $\begin{array}{c}2.0 \\
(0.7 \text { to } 5.3)\end{array}$ & & $\begin{array}{c}2.1 \\
\text { (0.6 to } 7.8)\end{array}$ & $\begin{array}{c}5.1 \\
(1.7 \text { to } 14.5)\end{array}$ & \\
\hline \multicolumn{9}{|l|}{ Vi vaccine: } \\
\hline Levin et $a^{42}$ & ND & Clinic & 21 & 24 & ND & NA & NA & ND \\
\hline Tacket et $\mathrm{al}^{44}$ & $20-24$ & Clinic & 19 & 0 & ND & NA & NA & 0 \\
\hline Klugman et $\mathrm{al}^{43}$ & $5-15$ & Field & 253 & $<1$ & 4 & NA & NA & ND \\
\hline Cumberland et $\mathrm{a}^{22}$ & $18-22$ & Clinic & 388 & $<1$ & 1 & NA & NA & ND \\
\hline Mirza et al ${ }^{45}$ & 5-15 & Field & 435 & 0 & 8 & NA & NA & ND \\
\hline $\begin{array}{l}\text { Pooled estimate } \\
(95 \% \mathrm{Cl})\end{array}$ & & & & $\begin{array}{c}1.1 \\
(0.1 \text { to } 12.3)\end{array}$ & $\begin{array}{c}3.7 \\
(1.3 \text { to } 9.6)\end{array}$ & & & $\begin{array}{c}0 \\
\text { (not defined) }\end{array}$ \\
\hline \multicolumn{9}{|c|}{ Whole cell vaccine (heat inactivated): } \\
\hline $\mathrm{YTC}^{23 *}$ & $5-50$ & Field & 214 & 9 & 5 & NA & NA & 11 \\
\hline Ashcroft et $\mathrm{al}^{6 *}$ & $5-15$ & Field & 193 & 13 & 61 & NA & NA & 14 \\
\hline $\mathrm{YTC}^{7 *}$ & NA & Field & 66 & 29 & ND & NA & NA & 17 \\
\hline Hejfec et $\mathrm{a}^{32}$ & $7-18$ & Field & 2621 & 30 & 19 & NA & NA & ND \\
\hline Hejfec et al ${ }^{33}$ & ND & Field & 3463 & 26 & 21 & NA & NA & ND \\
\hline Hejfec et $\mathrm{al}^{35}$ & $7-20$ & Field & 2157 & 13 & 13 & NA & NA & ND \\
\hline Dimache et $\mathrm{al}^{24}$ & $16-18$ & Field & 94 & 27 & ND & NA & NA & ND \\
\hline Dimache et $\mathrm{al}^{25}$ & 21 & Clinic & 113 & 1 & ND & NA & NA & ND \\
\hline Dimache $^{26}$ & 20 & Field & 100 & 34 & ND & NA & NA & 2 \\
\hline Cumberland et $\mathrm{a}^{22}$ & $18-22$ & Clinic & 390 & 2 & 20 & NA & NA & ND \\
\hline $\begin{array}{l}\text { Pooled estimate } \\
(95 \% \mathrm{Cl})\end{array}$ & & & & $\begin{array}{c}15.7 \\
(11.5 \text { to } 21.2)\end{array}$ & $\begin{array}{c}20.0 \\
\text { (12.9 to } 29.7)\end{array}$ & & & $\begin{array}{c}10.0 \\
\text { (6.0 to } 16.2)\end{array}$ \\
\hline
\end{tabular}

YTC=Yugoslav Typhoid Commission

NA-not applicable.

$\mathrm{ND}=$ not described in study.

${ }^{*}$ Provided estimates of incidence of adverse events at different time points without providing data on overall incidence. Data presented correspond to incidence at 24 hours after vaccination.

diarrhoea. Ten per cent of subjects missed school or work after receiving the whole cell vaccine; only one study of the newer vaccines specifically commented on this outcome.

\section{Discussion}

In this meta-analysis the three year efficacy of the whole cell vaccines exceeded the efficacy of the Ty21a vaccine. Although individual trial estimates varied widely for two doses of the inactivated whole cell vaccines and three doses of Ty21a, the pooled estimates from this study were associated with much narrower confidence intervals. The efficacy estimate for the Vi vaccine, though imprecise, was similar to the estimate for the Ty2la vaccine.

In the absence of trials directly comparing typhoid vaccines, this analysis of controlled trials provides the most valid means of assessing such vaccines, and it delineates the efficacy of these vaccines more precisely than previous qualitative reviews, which have tended to equate their efficacy. ${ }^{28}$ When each year of follow up was examined separately the whole cell vaccines provided significant protection for five years, Ty2la vaccine for four years, and $\mathrm{Vi}$ vaccine for two years. With regimens using fewer doses of the whole cell and Ty21a vaccines, protection did not last as long as with regimens of standard numbers of doses.

The superior efficacy of the whole cell vaccines must be weighed against their higher incidence of adverse events. The incidence of fever with these vaccines was notably higher than with the Ty21a and Vi vaccines. A further indication of the toxicity of the whole cell (heat inactivated) vaccines is that $10 \%$ of individuals missed school or work after vaccination. This study supports a general clinical impression that the newer vaccines are associated with much lower toxicity than the whole cell vaccines.

\section{Vaccination programmes for nations where typhoid is endemic}

Whether a routine vaccination programme using any of these moderately effective vaccines would be useful in reducing the incidence of typhoid in developing countries-where attack rates may approximate $1 \%$ per year $^{27}$-is a complex issue. The effectiveness of these vaccines in public health practice will be different from the efficacy noted in field trials, as the result of a vaccination programme depends on additional factors that influence immunity at population level ("herd immunity"). These factors include the demographic distribution of susceptible and immune individuals in the population, the number of secondary cases that arise from each primary case, the degree of vaccination coverage achieved, and the duration of natural and vaccine associated immunity. ${ }^{46}$

Herd immunity may have a role in the epidemiology of typhoid fever. A typhoid control programme in Thailand, based in part on use of a heat inactivated vaccine, resulted in a 10-fold decrease in rates of 
disease over eight years in all examined age groups, despite vaccination only of school age children. ${ }^{47}$ The number of cases of paratyphoid fever remained unchanged, suggesting that the widely based decrease in cases of typhoid could be attributed to immunisation and herd immunity and not to general improvements in sanitation. Similarly, decreases in typhoid cases were noted among an unvaccinated population at the onset of trials of Ty21a vaccine in neighbouring areas. ${ }^{48}$

The relatively precise estimates of efficacy and toxicity that this study provides can be used to model the potential impact of a vaccination programme in nations where typhoid is endemic. We did not find a relation between vaccine efficacy and an individual's risk of disease (as reflected by control incidences varying from 6 to 810 cases per 100000 population per year) or between efficacy and age (though we were limited by incomplete reporting of age specific data). Because the whole cell vaccines provide the greatest protection for the longest duration, these vaccines may be best suited among available vaccines for control programmes. The decision regarding which vaccine, if any, would be appropriate for typhoid control in endemic nations depends on a careful weighing of the benefits of vaccination and the side effects and costs. Currently none of the typhoid vaccines is administered as part of the World Health Organisation's expanded programme on immunisation, which targets children aged under 1 year.

The conclusions of this meta-analysis should also be interpreted in the context of variations in dose and formulation of Ty21a vaccine. Whereas Ty21a vaccine is available in most countries as a three dose regimen of enteric coated capsules, it is licensed for administration to travellers in the United States and Canada as a four dose series. A three year Chilean trial reported that four doses of the Ty 21 a vaccine is $40 \%$ more effective than three doses ${ }^{49}$; we did not include this study in our meta-analysis because it lacked a suitable control arm. Furthermore, our analysis suggests that the liquid formulation of Ty2la vaccine may be more effective than the enteric capsule formulation ${ }^{14} 27$; 28 this liquid formulation is only now becoming commercially available. No data have been published examining whether four doses of any formulation of Ty21a vaccine provides protection for longer than three years.

\section{Vaccination for travellers}

Further research is needed to determine the efficacy of these vaccines in travellers to countries where typhoid is endemic. Though the overall incidence of disease in such travellers is low $(<20$ per 100000$)$, higher risk travellers constitute an important target group for typhoid vaccines. ${ }^{29}$ None of the trials in this study examined this population, and it is not clear whether efficacy for travellers can be extrapolated from efficacy of vaccines in endemic countries, where individuals may already have some baseline immunity due to unapparent infections..$^{50} \mathrm{~A}$ single case-control study of travellers to India estimated the efficacy of the Ty21a vaccine to be $23 \%,{ }^{51}$ considerably lower than our estimate for populations living in countries where typhoid is endemic.

Our study suggests that $\mathrm{Vi}$ vaccine might be an appropriate choice of vaccine for short term travellers: protection need not be prolonged, and the efficacy of
- Typhoid fever is an important public health problem in the developing world, but the efficacy of currently available vaccines has remained uncertain

- This meta-analysis of 17 vaccine efficacy trials and 20 toxicity studies of the whole cell, Ty21a, and Vi typhoid vaccines showed that whole cell vaccines probably offer the greatest protection for the longest time

- These vaccines, however, were associated with higher toxicity than the Ty2la and Vi vaccines

- The decision about whether to vaccinate against typhoid fever-and which vaccine to use-depends on the individual setting

- Efficacy trials of vaccines should use standardised trial designs and methods of reporting

this vaccine is similar to that of the whole cell vaccines during the first year after vaccination. Also, the Vi vaccine has lower toxicity than the whole cell vaccines. Similarly, four doses of Ty21a vaccine may be effective prophylaxis for travellers. Though typhoid vaccination of travellers may not be cost effective, ${ }^{10}$ travellers may still opt for vaccination after discussing with their doctors the benefits and side effects.

The apparent efficacy of an intervention may vary with differences in trial design..$^{52}$ Only 8 of the 17 trials provided descriptions of both randomisation methods and blinding of treatment assignment during follow up. Because there were few trials in each vaccine class, we were unable to analyse the effect of differences in study design on reported efficacy. These inconsistencies in study design and reporting highlight the need for better international cooperation for trials of vaccines that have potential importance for public health. ${ }^{53}$

Whether the higher toxicity of whole cell vaccines compared with the Ty2la or Vi vaccines outweighs their added efficacy will likely depend on the setting in which the vaccine is administered. This analysis provides useful data for comparing these vaccines.

Contributors: EAE was the principal investigator for the study. He conceived of the study through discussions with MLB. EAE performed the literature search. EAE and MEF extracted the data. JL served as the expert on the design of the meta-analysis and the methods used. MLB served as the expert on vaccine use in developing countries, with special reference to typhoid fever. All four authors were involved in designing the study, analysing the data, and writing and reviewing drafts of the manuscript; EAE was the primary author of the manuscript. Michael D Aubert retrieved references, and Christopher $\mathrm{H}$ Schmid provided statistical advice. EAE and MLB are the guarantors.

Funding: EAE received support from the Agency for Health Care Policy and Research (grant No T32 HS00060).

Conflict of interest: None.

1 Institute of Medicine. New vaccine development:establishing priorities. Washington, DC: National Academy Press, 1986.

Bennish ML. Immunization against Salmonella typhi. Infect Dis Clin Pract 1995;4:114-22.

3 Shadish WR, Haddock CK. In: Cooper H, Hedges LV, eds. The handbook of research synthesis. New York: Russell Sage Foundation, 1994:262.

4 Pearson K. Report on certain enteric fever inoculation statistics. BMJ 1904;ii:1243-6. 
5 Yugoslav Typhoid Commission. A controlled field trial of the effectiveness of phenol and alcohol typhoid vaccines: final report. Bull WHO 1962;26:357-69.

6 Ashcroft MT, Ritchie JM, Nicholson CC. Controlled field trial in British Guiana school children of heat-killed phenolized and acetone-killed lyophilized vaccines. Am J Hyg 1964;79:196-206.

7 Yugoslav Typhoid Commission. A controlled field trial of the effectiveness of acetone-dried and inactivated and heat-phenolinactivated typhoid vaccines in Yugoslavia. Bull WHO 1964;30:623-30.

8 Centers for Disease Control and Prevention. Typhoid immunization. Recommendations of the Advisory Committee on Immunization Practices. MMWR 1994;43:1-8.

9 Typhoid vaccination: weighing the options [editorial]. Lancet 1992;340:341-2.

10 Behrens RH, Roberts JA. Is travel prophylaxis worth while? Economic appraisal of prophylactic measures against malaria, hepatitis $\mathrm{A}$, and typhoid in travellers. BMJ 1994;309:918-22.

11 The Cochrane Library. Cochrane Collaboration; 1997, Issue 3. Oxford: Update Software; 1997. Updated quarterly.

12 Ashcroft MT, Singh B, Nicholson CC, Ritchie JM, Sobryan E, Williams F. A seven-year field trial of two typhoid vaccines in Guyana. Lancet 1967;ii:1056-9.

13 Levine MM, Ferreccio C, Black RE, Germanier R, Chilean Typhoid Committee. Large-scale field trial of Ty21a live oral typhoid vaccine in enteric-coated capsule formulation. Lancet 1987;i:1049-52.

14 Levine MM, Ferreccio C, Cryz S, Ortiz E. Comparison of enteric-coated capsules and liquid formulation of Ty2 1a typhoid vaccine in randomised controlled field trial. Lancet 1990;336:891-4.

15 Polish Typhoid Committee. Controlled field trials and laboratory studies on the effectiveness of typhoid vaccines in Poland, 1961-64. Final report. Bull WHO 1966;34:211-22.

16 Tapa S, Cvjetanovic B. Controlled field trial on the effectiveness of one and two doses of acetone-inactivated and dried vaccine. Bull WHO 1975;52:75-80.

17 Ioannidis JPA, Cappelleri JC, Lau J, Skolnik PR, Melville B, Chalmers TC, et al. Early or deferred zidovudine therapy in HIV-infected patients without an AIDS-defining illness: a meta-analysis. Ann Intern Med 1995; 122:856-66.

18 Laird NM, Mosteller F. Some statistical methods for combining experimental results. Int J Tech Assess Health Care 1990;6:5-30.

19 McIntosh MW. The population risk as an explanatory variable in research synthesis of clinical trials. Stat Med 1996;15:1713-28.

20 Greenland S. Quantitative methods in the review of epidemiologic literature. Epidemiol Rev 1987;9:1-30.

21 Cryz SJ, Que JU, Levine MM, Wiedermann G, Kollaritsch H. Safety and immunogenicity of a live oral bivalent typhoid fever (Salmonella typhi Ty21a)-cholera (Vibrio cholerae CVD 103-HgR) vaccine in healthy adults. Infect Immun 1995;63:1336-9.

22 Cumberland NS, St Clair Roberts J, Arnold WSG, Patel RK, Bowker CH Typhoid Vi: a less reactogenic vaccine. J Int Med Res 1992;20:247-53.

23 Yugoslav Typhoid Commission. Field and laboratory studies with typhoid vaccines. A preliminary report. Bull WHO 1957;16:897-910.

24 Dimache G, Dimache V, Pavel A, Crottoru M. Intradermal versus subcutaneous typhoid vaccination. Arch Roum Path Exp Microbiol 1981;40:143-7.

25 Dimache G, Croitoru M, Nicolae IN. Subcutaneous versus intradermal typhoid vaccination by "jet injector" apparatus. Arch Roum Path Exp Microbiol 1982:41:259-64.

26 Dimache G. The comparative effectiveness, under epidemic conditions, of the intradermal versus subcutaneous antityphoid vaccination estimated by epidemiological surveillance and laboratory tests. Zentralbl Bakteriol $A$ 1986;262:220-229.

27 Simanjuntak CH, Paleologo FP, Punjabi NH, Darmowigoto R, Soeprawoto, Totosudirjo $\mathrm{H}$, et al. Oral immunisation against typhoid fever in Indonesia with Ty21 a vaccine. Lancet 1991:338:1055-9.

28 Wahdan MH, Sérié C, Cerisier Y, Sallam S, Germanier R. A controlled field trial of live Salmonella typhi strain Ty 21a oral vaccine against typhoid: three year results. J Infect Dis 1982;145:292-5.

29 Black RE, Levine MM, Ferreccio C, Clements ML, Lanata C, Rooney J, et al. Efficacy of one or two doses of Ty21a Salmonella typhi vaccine in enteric coated capsules in a controlled field trial. Vaccine 1990;8:81-4

30 Acharya IL, Lowe CU, Thapa R, Gurubacharya VL, Shrestha MB, Cadoz $\mathrm{M}$, et al. Prevention of typhoid fever in Nepal with the Vi capsular polysaccharide of Salmonella typhi: a preliminary report. $N$ Engl J Med 1987;317:1101-4.

31 Klugman KP, Koornhof HJ, Robbins JB, Le Cam NN. Immunogenicity, efficacy and serological correlate of protection of Salmonella typhi Vi capsular polysaccharide vaccine three years after immunization. Vaccine 1996;14:435-8.

32 Hejfec LB. Results of the study of typhoid vaccines in four controlled field trials in the USSR. Bull WHO 1965;32:1-14.

33 Hejfec LB, Salmin LV, Lejtman MZ, Kuz'minova ML, Vasil'eva AV, Levina LA, et al. A controlled field trial and laboratory study of five typhoid vaccines in the USSR. Bull WHO 1966;34:321-39.

34 Hejfec LB, Levina LA, Kuz'minova ML, Salmin LV, Slavina AM, Vasil'eva AV. Controlled field trials of paratyphoid B vaccine and evaluation of the effectiveness of a single administration of typhoid vaccine. Bull WHO effectiveness of

35 Hejfec LB, Levina LA, Kuz'minova ML, Slavina AM, Drozd AK, Tonojan IA, et al. A controlled field trial to evaluate the protective capacity of a single dose of acetone-killed agar-grown and heat-killed broth-grown typhoid vaccines. Bull WHO 1969;40:903-7.

36 Levine MM, Tacket CO, Herrington D, Losonsky G, Murphy J, Ferreccio C. The current status of typhoid vaccine development and clinical trials with typhoid vaccines. Southeast Asian J Trop Med Public Health 1988;19:459-69.
37 Levine MM, Taylor DN, Ferreccio C. Typhoid vaccines come of age. Pediatr Infect Dis J 1989;8:374-81.

38 Gilman RH, Hornick RB, Woodward WE, DuPont HL, Snyder MJ, Levine $\mathrm{MM}$, et al. Evaluation of a UDP-glucose-4-epimeraseless mutant of Salmonella typhi as a live oral vaccine. J Infect Dis 1977;136:717-23.

39 Murphy JR, Grez L, Schlesinger L, Ferreccio C, Baqar S, Munoz C, et al. Immunogenicity of Salmonella typhi Ty21a vaccine for young children. Infect Immun 1991;59:4291-3.

40 Rahman S, Barr W, Hilton E. Use of oral typhoid vaccine strain Ty21a in a New York state travel immunization facility. Am J Trop Med Hyg 1993;48:823-6.

41 Cryz SJ, Vanprapar N, Thisyakorn U, Olanratmanee T, Losonsky G, Levine MM, et al. Safety and immunogenicity of Salmonella typhi Ty21a vaccine in young Thai children. Infect Immun 1993;61:1149-51.

42 Levin DM, Wong KH, Reynolds HY, Sutton A, Northrup RS. Vi antigen from Salmonella typhosa and immunity against typhoid fever. II. Safety and antigenicity in humans. Infect Immun 1975;12:1290-4.

43 Klugman KP, Gilbertson IT, Koornhof HJ, Robbins JB, Schneerson R, Schulz D, et al. Protective activity of Vi capsular polysaccharide vaccine against typhoid fever. Lancet 1987;ii:1165-9.

44 Tacket CO, Ferreccio C, Robbins JB, Tsai C, Schulz D, Cadoz M, et al Safety and immunogenicity of two Salmonella typhi Vi capsular polysaccharide vaccines. J Infect Dis 1986;154:342-5.

45 Mirza NB, Wamola IA, Estambale BA, Mbithi E, Poillet M. Typhim Vi vaccine against typhoid fever: a clinical trial in Kenya. East African Med J 1995;72:162-4.

46 Anderson RM, May RM. Immunisation and herd immunity. Lancet 1990;335:641-5

47 Bodhidatta L, Taylor DN, Thisyakorn U, Echeverria P. Control of typhoid fever in Bangkok, Thailand, by annual immunization of schoolchildren with parenteral typhoid vaccine. Rev Infect Dis 1987;9:841-5.

48 Levine MM, Ferreccio C, Black RE, Tacket CO, Germanier R, Chilean Typhoid Committee. Progress in vaccines against typhoid fever. Rev Infect Dis 1989;11:S552-67.

49 Ferreccio C, Levine MM, Rodriguez H, Contreras R, Chilean Typhoid Committee. Comparative efficacy of two, three, or four doses of TY21 live oral typhoid vaccine in enteric-coated capsules: a field trial in an endemic area. J Infec Dis 1989;159:766-9.

50 Joo I. Benefits versus risk factors in cholera and typhoid immunization. Develop Biol Standard 1979:43:47-52.

51 Hirschel B, Wuthrich R, Somaini B, Steffen R. Inefficacy of the commercial live oral Ty 21a vaccine in the prevention of typhoid fever. Eur J Clin Microbiol 1985;4:295-8.

52 Standards of Reporting Trials Group. A proposal for structured reporting of randomized controlled trials. JAMA 1994;272:1926-31.

53 Begg C, Cho M, Eastwood S, Horton R, Moher D, Olkin I, et al. Improving the quality of reporting of randomized controlled trials. The CONSORT statement. JAMA 1996;276:637-9.

(Accepted 8 September 1997)

\section{Retraction}

First myocardial infarction in patients of Indian and European origin: comparison of risk factors, management, and long term outcome

The authors of this paper (N Shaukat, J Lear, A Lowy, S Fletcher, D P de Bono, K L Woods. BMJ 1997;314:550-4) have written: "Further examination of the data on which this paper was based, in the context of another project, has revealed important inaccuracies such that the conclusions of the paper cannot be sustained. We therefore wish to withdraw it unreservedly."

\section{Corrections}

Household survey of locomotor disability caused by poliomyelitis and landmines in Afghanistan

An error occurred in this paper by Lambert and colleagues (29 November, pp 1424-5). The footnote to the table should have read: 3 children had received an injection before the onset of paralysis and would not be included if WHO definition was strictly applied (not that 3 children received an injection of polio vaccine).

Systematic overview of co-proxamol to assess analgesic effects of addition of dextropropoxyphene to paracetamol

An error occurred in this paper by A Li Wan Po and W Y Zhang (13 December, pp 1565-71). Co-proxamol was incorrectly described as containing $650 \mathrm{mg}$ paracetamol and 32.5 mg dextropropoxyphene hydrochloride. The third sentence of the introduction should have read: "Co-proxamol, a combination product containing $325 \mathrm{mg}$ paracetamol and 32.5 mg dextropropoxyphene hydrochloride, was the most popular prescription, accounting for $35 \%$." 